\title{
Commoning the smart city: A case for a public Internet provision.
}

\author{
Paolo Cardullo \\ Technology Adoption Group \\ School of Business \& Social Science Institute \\ Maynooth University \\ Paolo.Cardullo@mu.ie \\ http://kiddingthecity.org
}

\begin{abstract}
As cities become more involved in data-driven processes of growth and governance, critical scholarship has highlighted the formidable issues around ownership, uses and the ethics of collecting, storing, and circulating such data. However, there has been less focus on the physical infrastructure as the 'last mile' problem for Internet access, between a revanchist perspective on the 'broken Internet' delivered by digital capitalism and the liberal rhetoric of the Internet as a human right. Through two case studies, the paper plots a pragmatic trajectory in the adoption of the Internet for people and 'things', in which city and users take different roles and responsibilities. It highlights benefits and challenges around the long-term sustainability and maintenance of the Internet as an infrastructure of the commons. An attention to 'commoning', instead, reveals the exclusionary or enabling practices the smart city might foster. Thus, the paper advocates for the direct involvement of the city and its citizens in maintaining and reproducing connectivity networks in the smart city.
\end{abstract}

Smart City; Public Internet; Commons; Commoning; Wi-Fi networks 


\section{Introduction}

'Smart city' has become such a loaded concept in policy discourses, academic papers, and industry reports, that it is difficult to provide an agreed definition. Some scholars highlight technological innovations (interconnected sensors, devices, servers, and algorithms for automated responses and data collection) and the opportunities such technologies offer as spatialised or collective intelligence, in terms of mobility and communication (e.g., Foth 2017; Picon 2015). Others, the new forms of governmentality these innovations produce by data streams which feed dynamically into management systems (Luque-Ayala and Marvin 2016; Sadowski and Pasquale 2015; Vanolo 2014). Kitchin $(2014,2016)$ puts emphasis on the epistemological underpinnings that relate urbanism to software-led sciences, contending that the current mode of production of smart cities is data-driven and this has become instrumental to the technocratic approach to urban issues. While some authors would favour a citizencentric model that fosters social innovation, civic engagement and transparent governance (e.g., Bria 2017; de Lange and de Waal 2013; Townsend 2013), for Hollands (2008) smart cities represent a technology-led stage in the process of neoliberalisation and gentrification of cities: a "high-tech variation of urban entrepreneurialism" (p. 305) that seeks to attract the creative class and evades notions of social justice.

Clearly, 'one size fits all' is not a feasible path in the smart city discourse. Shelton, Zook and Wiig (2015) warn about the complexity and diversity of the ways in which the smart city idea(l) is implemented: "smart city interventions are always the outcomes of existing social and spatial constellations of urban governance and the built environment” (p. 14). The paper attends to this call by showing a variety in the 'last mile' Internet provision, highlighting their long-term sustainability issues - I frame these in a debate around 'commoning' and maintenance of the commons. Although smart cities are not just about broadband connectivity, access to unlimited, super-fast and possibly free Internet has been symbolically crucial to the making of smart cities: the Internet is thought to be the smart city backbone, "the backbone of modern society, a platform for businesses, governments and citizens to exchange news and views, as well as to provide services, whether essential or trivial” (The Digital Agenda for Europe). ${ }^{i}$ However, private and communitarian actors often gloss over the fact that the Internet as infrastructure is a form of 'public value' embedded in a longer term strategy of technological and infrastructural innovation (Mazzucato 2018). Even in the scholarly community, the Internet backbone is often related to research papers from an engineering background, which generally discuss network protocols, resilience, and security, 
but not social ecologies and political issues around its deployment. Between a sort of revanchism around the 'broken Internet' of digital capitalism and the liberal rhetoric of the Internet as a human right, only recently media studies have gone through the so-called 'infrastructural turn' with the aim of focusing on "scale, industry logics, and policy" in the everyday uses of digital platforms, on the "various material assemblages" that make them, and on "the business of Internet service provision" such platforms attend to (Plantin and Punathambekar 2018). Instead, this paper takes a pragmatic and empirical approach considering different ecologies of implementation, control, and maintenance of the Internet as smart city infrastructure, beyond the present neoliberal landscape of privatised and quasimonopolistic provision.

\section{The 'smart' in the smart city}

One effective way to grasp the diversity of smart city initiatives, and their pervasiveness in every aspect of daily life, is by following Kitchin (2016) who lists these through their different domains: from the very functioning of city governance and security to the intimate spaces of home and the body, sensors and related software for extraction, transmission, and eventual analysis of data are implemented and used by a vast number of city dwellers, organisations, service providers, critical infrastructures, and city executives. This incredible variety of smart city solutions presents also some rather consistent characteristics, which I try to group in the following three points.

First, smart technologies are always somehow linked to an algorithm-led response, even only for a card payment or for an instance of communication. Ultimately, algorithmic functions represent the 'smart' bit in smart technology. They involve always some transmission of information or data from one agent (machinic, human-operated, or human) to another. Recording, storing or transmission are the modus operandi of smart technologies, their reasons to be. Therefore, while traditionally the Internet has facilitated interaction between humans, the current socio-technological landscape starts being dominated by different configurations we can group under the 'Internet of Things' (IoT). These 'things' are digital devices that typically have a communication interface, processing and storage units, and sensors for detection of environmental changes or for service provision to other clients. The combination of short-range mesh networks and the wider cellular network can provide wireless connectivity to these 'things' in order to exchange data to the wider Internet. While 
transmission between people and machines favours a degree of communication that would be otherwise impossible (typically in 'Voice Over IP' calls across the globe), on a deeper level exchange happens in milliseconds between algorithms that regulate many other aspects of daily life, such as financial interfaces and banking transactions, or IoT devices at home and in the urban environment.

Second, and consequently, this variety of smart technologies are in desperate need of some form of connectivity or infrastructural support for data exchange. The smart city paradigm is based on the notion of connectivity among heterogeneous smart city objects via networks that use short-range communication technologies and, eventually, Internet gateways. In the future smart city, providing flawless connectivity will probably become a real challenge as the density of connected devices that have multi-radio capabilities increases. Thus, the battle for speed and reliability of Internet connectivity has become a synonymous of city growth, competitivity and progress: a brand, like in the case study of Chattanooga city, below. Inequality of access (for people and 'things') is indeed a striking paradox at the heart of the smart city: how can this super connected and increasingly complex urban environment work without a strong backbone and its capillary distribution to as many users / customers / citizens / 'things' as possible? The booming IoT risks increasing the exclusivity gap (super connected areas or hubs) and splintering service provision further, as observed by pioneering studies on digital cities (Graham \& Marvin, 2001).

Third, a major obstacle for the adoption of smart technologies seems to be exactly this scarcity, which capitalism is so good at creating via market imperatives of privatization and efficiency: Fibre-to-Home, for instance, is almost everywhere in the hands of Big Cable which hold often a quasi-monopolist position. Giant providers control Internet provision acting as gateway for people and 'things', metering and throttling connectivity at a high price and slowing down at will. A splintered network is probably more difficult to regulate and develop: for instance, Korea's resistance to early privatization allowed high levels of public investment in broadband infrastructure (Curran 2018). Whatever the means of delivering it to the overall population, for some, the Internet has to be considered a critical infrastructure like water or heath (one of the rights that makes the 'right to the smart city' operative, so to speak): “connecting communities to the web is the pathway, not the end goal, for true equity and empowerment” (Mabud and Seitz-Brown 2017). 
The variety and pervasiveness of smart technologies in the everyday life of cities raise, however, a formidable array of ethical issues in relation to extraction and treatment of data, surveillance and control, as well as privacy, consent and disclosure of personal and sometimes sensitive data for any purpose. Technology critic Evgeny Morozov calls it "data extractivism” (2015; see also Mezzadra and Neilson 2017), others “data colonialism” (Thatcher, O’Sullivan, and Mahmoudi 2016) or "platform capitalism” (e.g., Shaw and Graham 2017). They all point to the extraordinary concentration of data produced through uses, consumption, and leisure that is, through life itself - in the hands of a few Silicon Valley's start-ups. Participation through the workings of smart technologies can thus come to the price of reduced privacy, nudging advices and more severe breaches of collective rights, such as mass surveillance. Neither, more Internet access equates to more freedom. As Couldry (2018) puts it, "While the Internet is often credited with bringing freedom, its most important feature is connection, not freedom”. And such 'connection' is not neutral. For instance, in their study of Facebook, Skeggs and Yuill (2018) argue the social media frenzy has masked the neoliberalisation process of subjectivity, the online performance of the self measured via metrics of appreciations, participation, and value exchange. While many reports insist that more megabits per second boost the economy, ${ }^{\text {ii }}$ the industry has appropriated the liberal rights discourse of Internet access as a human right claim - famously, Facebook wanted to launch 'Free Basics' in India in 2015 and operate an off-line text-only policy, 'Facebook Zero', for non smart phone users in Myanmar (see Plantin and Punathambekar 2018). Every city has a different story to tell, but when Facebook agrees with telephonic companies for free but locked-in access, while the cost of going private takes a substantial part of a family income, it comes with no surprise that most people think that "Facebook is the Internet" iii With platform capitalism becoming infrastructures, there is a poignant question to be asked: in a nutshell, would the Internet be only a gateway to train a wider reserve army of digital workers?

The paper does not attempt to answer this question. However, the two case studies below suggest a pragmatic approach, showing different ecologies of implementation, control, and maintenance of the network which delivers the Internet. In the present scenario of a growing demand for connectivity from people to 'things', it is easy to believe that the capacity of the networks will be increased and expanded. We can move the above question to the supply side and ask: how and in whose terms is this infrastructural development going to happen? To repeat, the issue of public availability and fair access to the Internet is not going to challenge the many faces of digital capitalism, but it might provide one possible gateway in the life 
cycle of data for more local control and accountability. At very least, the paper suggests to revert the vicious circle of privatisation of infrastructures and the consequent centralisation of the Internet in the hands of very few and powerful companies - this is particularly acute in the US for a series of historical reasons (Hu 2015). Beyond the neoliberal rhetoric of the 'market failure', public resources and skills could be turned towards more fair and open infrastructures, by bolstering different approaches to commoning - the contested process of delivering, protecting and maintaining the infrastructure as a commons, to which I turn next.

\section{Commons and commoning in the smart city}

A useful line of thought in the vast literature on commons suggests that this concerns not so much the conflict between public and private (e.g., De Angelis 2001; Stavrides 2016). Rather, commons manifests itself, historically, as the locus within which peoples' social reproduction is put into practice. The confusion is exactly at the point of departure from the idea of the commons that emerges, in medieval England, as a fight against the enclosures of land. According to Illich (1982), people saw this common space not as a "non-private space”, rather as the space where their everyday subsistence was guaranteed. Using the commons was an act of temporary appropriation, an everyday practice for the purpose of social reproduction: thus, a commons is determined not so much by its proprietary regime, but by the uses and practices around it. A common good, in other words, has no ontological substance in itself. It becomes a commons because of the qualitative relationship with one or more subjects; it is the use value, of a place or an object, that makes it relevant to the commons: "you don't have a common good, you share in common good” (Mattei cited in Iaione 2012). For McLaren and Agyeman (2015), “sharing and cooperation are universal values and behaviours" and, therefore, "sharing is an opportunity to release [people’s cooperative] capacity, confined by competitive markets and bureaucratic states” (p. 24). So, if cities are shared creations with shared public services, streets, mass transit, and shared spaces, "truly smart cities must also be sharing cities” (ibidem).

Some scholars therefore prefer to put the emphasis on 'commoning', a set of practices which both "actively seek[s] to integrate resources from the state and capital into commons circuits” (Birkinbine 2018), and reproduces the commons through sharing resources in solidarity networks. The latter shifts our focus on the long-term maintenance of the commons: “the true challenge of the commons”, according to Huron (2015:973). De Angelis (2017) 
argues that this hinges around the daily practices of the community of interest involved, and around the bundle of rights attached and their enforcement, which should protect the commons and guarantee its reproduction. Thus, commoning highlights the contested, openended, and political character of urban commons (De Angelis and Stavrides 2010). In this sense, commoning is a "grass-roots project to build a new form of consensus around a different set of values and ethical codes” (Susser 2017:1). But, what does this mean nowadays when most people's livelihood, especially in the Global North, might depend on access to information, communication and coding (Lash 2002)? What is commons and what the value of commoning in a city increasingly regulated by processes of data acquisition and exchange?

For Hardt and Negri (2009), the results of advanced capitalist production are expressed as a 'collective intelligence' unlocked by the forced multiplicity and proximity that urban living implies. Value is created now by life itself, in mundane and very material practices of urban dwelling, social encounters, and social reproduction. Production extends to the city in its totality: it is the social factory 4.0. Thus, many activists and scholars advocate for 'digital commons', where ownership and control of data become democratic practices of appropriation of technology. For instance, the 'right to the digital city' (de Lange and de Waal 2013) is centred on an alternative form of ownership of data, and the 'informational right to the city' (Shaw and Graham 2017) is grounded in a "sense of belonging to a collective place ... and [a] willingness to share a private resource with the collective”. At least, citizens should have the right to understand what data are being generated about them, how these are compiled into information and the uses to which they are put (see Kitchin 2016). Moreover, rewards from data ought to be socially shared or re-distributed both within the Public and within communities of practice (see Mazzucato 2018). Other solutions in this respect have included renewed calls for a form of 'basic social income' which acknowledges the smart city as a 'social factory', but also considers labour as producer of use value beyond capitalist forms of production and appropriation (e.g., Monnier and Vercellone 2017).

Partly acknowledging this, forms of democratisation of data and software are not per se immune of falling into the "post-political trap of technological determinism” (McLaren \& Agyeman, 2015, p. 201): there is a risk these initiatives foster 'commons' as a goal in itself, rather than 'commoning' as the process that leads to such a goal. Hardt and Negri (2009) call the new digital commons as "immaterial"; however, each commons presents a new set of social relations and spatial organisations. Thus, a materialist critique of digital commons 
(information, knowledge, data, software, etc.) ought to centre on daily practices of inhabitation and social reproduction. For Henry Lefebvre ([1967] 1996), urban space is a "work of art" of its users: it is appropriated by the everyday practices of the people who inhabit it. In this guise, the right to the city is "a right to change ourselves by changing the city more after our heart's desire" (Harvey 2003:1). This is a space ready to accommodate citizens' political claims: according to Marcuse's reading of Lefebvre (2009), this is the most radical idea he brings forth because it opens both to those people deprived of material subsistence and legal rights (a cry) and to alternative futures (and a demand). In other words, pursuing the 'right to the smart city' means creating cities that are not rooted in and driven-by technological capitalism and solutionism (see Cardullo, Kitchin, and Di Feliciantonio 2019). As a consequence, we can try to reframe the commons from the classic triad Private/Public/Commons to the emerging configuration of Capitalism/City/Commons (see De Angelis, 2017). Here, the scale of reference is at the city and infra-city level, while the struggle for appropriation of value moves iteratively through the two circuits for creation and circulation of wealth and well-being: the circuit of capital and that of the commons.

It is through this agonistic, dynamic, and place-based lens that I understand public provision of the Internet. The paper starts advocating for a policy direction alternative to the prevalent neoliberal mode of making cities 'smart': this would include municipalisation and democratic governance of critical infrastructures (including 'data infrastructure' and the Internet) and Public Commons Partnerships between the city, cooperatives, and social movements.

\section{Maintaining the Internet as a commons}

In this section, I discuss maintenance of urban commons in the smart city by presenting very briefly two case studies around ecologies of the Internet provision and their relation with commoning. These draw on previous ethnographic research on a communitarian wireless network in inner-city London (Cardullo 2017), more recent interviews around citizen-focused European smart city projects (Cardullo and Kitchin 2018b), and secondary sources from an ongoing research on this matter (see Cardullo 2015; Cardullo and Roio forthcoming). The first case study concerns the provision of municipal extra-large broadband in Chattanooga, Tennessee, and discusses public ownership of the Internet, although with a critical eye to urban governance and the roles citizens have in its overall ecology. A public-led provision of 
the Internet as envisioned here, in fact, would not work without different degrees of involvement from users and communities of practice: there is plenty of intelligence in the ethos and practices of community-led projects and in their informal uses of infrastructures, which cities can harvest in order to become more technologically inclusive and competitive. Thus, the second case revisits an ethnographic account I wrote around a community wireless network in inner-city London called OWN(Cardullo 2017), reflecting on its long-term sustainability through commoning.

\section{Chattanooga, the 'Gig City'}

Although fast connectivity is crucial to the development of data capitalism, the backbone on which networked technologies and people exchange data, is often assumed. As Mazzucato has been suggesting for some time (e.g., Lazonick and Mazzucato 2013), the private sector and the dominant neoliberal discourse downplay massively the role of the public in driving innovation and growth via core infrastructures, investments in skills and literacy, and more generally in taking on board the political-economic risks of failure. Similarly, $\mathrm{Hu}$ (2015:XVII) reminds that "the all-but-forgotten infrastructures that undergird the cloud's physical origins [are] often originated in a state's military apparatus”, where 'the cloud' is a catchy metaphor for the Internet: “a cultural fantasy, always more than its present-day technological manifestation” (p. 97).

This is never been more true than for Chattanooga, Tennessee, which in 2010 was the first city in the United States to offer 1 Gbps high-speed Internet (at the time, over 200 times faster than the national average), thus transforming the image of a polluted and failing city into the thriving 'Gig City’ (Kitheka et al. 2016). More notably, this super-fast Internet was offered via the municipal and non-profit Electric Power Board, making it the largest public investment in the US on the matter (EPB 2015). This mid-sized Tennessee city (170,000 people) made the headlines again in 2015 when it implemented the world's first communitywide 10Gbps Internet service. This is particular relevant in the context of the US, where Internet activists have long complained of the widening digital divide caused by private contractors dis-investment (the so-called 'Big Cable': private giant providers such as Comcast and AT\&T), which have left behind small and rural towns and impoverished neighbourhoods (e.g., Gonzalez 2018). ${ }^{\text {iv }}$ 
The Chattanooga case study offers interesting points for the debate on public infrastructure, governance and commoning in the smart city. First, it dismantles a few myths: that the public is always behind the technological curve, and thus needs private consultancy, interventions and skills (see Kitchin, Coletta, Evans, Heaphy, \& MacDonncha, 2017; Mazzucato, 2018); and that the public is slow, unreliable and inefficient in delivering - EPB completed its ambitious project much earlier than planned using a federal loan issued to implement cables for its electric smart grid (Davidson and Santorelli 2015). Just to give a sense of this town's achievement, in September 2016 the European Commission adopted its strategy on connectivity, a European 'Gigabit Society', with the main strategic objective to give $1 \mathrm{Gbps}$ to all schools, transport hubs and main providers of public services and digitally intensive enterprise by 2025: Chattanooga city realised this goal, at a much smaller scale, 25 years earlier and did it with public investments (that is, not solely to overcome 'market failure', but as a strategic and planned political decision).

Second, the case study highlights the relevance of the urban scale vis-a-vis county, state and federal scales, whose legislations have hindered rather than facilitated it (e.g., positing limits to EPB pricing policy and geographical expansion). In other words, the City inverted the cycle of privatizations and market-led solutions, in a particularly hostile environment: Big Cable and the Conservatives brought forward many legal challenges to Chattanooga City, and even TV commercials warning against the perils of public investments (Rushe 2014), in order to guarantee a 'free market'.

Third, the EPB fibre disrupts powerfully the Net Neutrality debate - that certain types of data should be throttled (slowed down), connections metered or charged at different rates, and certain sites blocked. At the present, these are hotly debated topics in the US (e.g., Gonzalez, 2018): as a consequence of the recent repealing of neutrality rules by the Federal Communications Commission (FCC), the cities of San Francisco, Seattle, and Boston are promising municipal broadband as an alternative which seems to gain momentum, especially among young voters.

Finally, and fourth, it is reasonable to think citizens can lobby the mid-sized town administrators more successfully than when acting as individual customers dealing with offshore call centres funded by Big Cable. Issues of governance, however, are case-specific and need deeper ethnographic engagement to be fully evaluated. A degree of scepticism that super fast Internet translates automatically into greater benefits for lay people is also due: if it takes 
“just 33 seconds to download a two-hour, high-definition film in Chattanooga” (Koebler, 2016), then we might want to ask how many films, or similar content, an average family can possibly use in one day? As an indirect evidence, EPB has now nearly 100k Internet customers (more than half of the civil and commercial residents of Chattanooga), which drops to about 20\% in its poorer neighbourhoods (Koebler, 2016): despite EPB offering half-price subsidized Internet for families that have students enrolled in school lunch programs, it appears that poorer residents prefer signing up with Comcast which offers a cheaper service although much slower and capped. In other words, what is the real use value of super-sized smart city initiatives like this? There is little doubt for me that Chattanooga has a typical 'smart city' strategy in mind: attraction of creative class via digital hubs, which bolster now several tech incubators and attract new businesses, including venture capital funds (Rushe, 2014). If the material and symbolic effects of this "Internet boomtown" (Koebler 2016) appear solid on the local economy, these are also assumed to 'trickle down' to the poor. More longitudinal research would be needed to evaluate the impact of 'the Gig' on the overall population, a third of which is said to be at risk of poverty and social exclusion.

It is important to note that other cities in the US have shown a different sensibility and approach to the issue of public Internet connectivity. For instance, New York City has installed a Wi-Fi network through the largest public housing complex in the US, its Queensbridge which houses over 7,000 residents in 95 buildings. Although NYC does not own the power company, as for the Chattanooga example, it managed to guarantee a free $25 \mathrm{Mbps}$ connection for all residents while offering premium rates for more demanding users. Installation and maintenance of this large networks was given via procurement to a third party company which managed to include the resident associations (at least with regards to information and consent) and some local people too (as trainees for the basic maintenance of the network) (Lewis-Kraus 2016). While Chattanooga remains a good example of efficient public service delivery, but apparently with limited impact on marginalised population, New York City experiments in public housing shows how utilities can be delivered as public service with redistributive effects, and even foster a more democratic model of urban governance.

Democratic governance is a double-faced Janus which offers benefits to both city and communities. It is an essential element for commoning practices, which would involve citizens as equal stakeholders with rights and entitlements, rather than as consumers of a 
private utility provision. But it is also necessary to the city in order to become part of the communitarian practices of its inhabitants. As Stavrides (2016) writes, any commons is held in a dialectic relationship with its users because "common space keeps on producing those who produce it”. He goes further suggesting that an essential feature for the perpetration of urban commons is the possibility of controlling and eventually revoking appointed leaders. Thus, researching the exclusionary practices of governance is important for understanding commoning, "the social process that creates and reproduces the commons" (De Angelis \& Stavrides, 2010). The move from the object to the action is crucial here because the emphasis is now on practices and agencies, from exchange value to use value, and from short-term returns to longer-term 'soft' outcomes. In the following case study around a community-led wireless network, I draw on the idea that 'commoning' is the long term modus operandi of the commons (e.g. De Angelis, 2017) and suggest this presents many challenges to the sustainability of technology-led grassroot initiatives.

\section{OWN: Informality and commoning}

Open Wireless Network started in 2008 from the rooftops of an iconic hack-space in Deptford, inner-city London. ${ }^{\text {vi }}$ It was a mesh of independent radios (nodes) which, by talking to each others and via ad-hoc gateways, provided extended broadband access to the immediate neighbourhood or passers-by in the reach of its wireless signal. Soon after its establishment, OWN peaked to almost 100 nodes and over 400 users at any one time, but in the last few years the project went through a period of decline since, with smartphone data network access as standard and a wider public provision in libraries and cafés, "some of the passion for independent Wi-Fi infrastructure building has fallen away” (Cardullo, 2017). Informality and commoning were key to the initial popularity of OWN. This is because OWN resulted in a great value for its users, responding to the local population's real need: a working class and racially diverse neighbourhood where digital divide and the gentrification pressure of displacement are high. The mesh of nodes particularly suited transient and migrant people, students and temporary workers, but also less wealthy locals, who did not have the capability to enrol in any official provision (for lack of residential documentation or money).

Community Wireless Mesh Networks (CWMNs) have been under development since early 2000s thanks to the work of ethical hackers and activists responding to a series of local needs and generally advocating a more open, neutral and democratic Internet (Cardullo and Roio 
forthcoming; Medosch 2003). Because of their inexpensive hardware and relative ease of assemblage, community networks have been deployed in many different ways, operating as specific solutions to local issues: therefore, each case is related to its wider digital and political ecosystem. Primarily, they have been an answer to excessive connectivity costs, allowing communities to share the cost of network deployment and the use and provision of resources, such as community radios, applications and data or listing of community events (for instance, both Ninux in Italy and Freifunk in Germany started in 2002 and grew to operate about 40k node). Adoption of CWMNs seems to have regained traction, especially in the US, because of the current Net Neutrality debate, where Big Cable ISPs have been lobbying for selective throttling, slowing down and metering, particularly in the Fibre-toHome market. Second, community networks have been providing 'last mile' access to remote localities where the market has 'failed' to deliver: this is how Guifi.net started in Catalonia in 2004, now bolstering over 33k operating nodes in much part of Spain. Third, community networks are deployed to fight data extractive practices and surveillance, since mesh are, ultimately, Intranet systems with locally controlled circulation and repositories of data. Obviously, dense residential areas work better for crowd-sourcing since they can enable resource pooling and commoning across the network (e.g., file-sharing, game modding, environmental data). This is the case of SNet in Havana, a wide and expanding mesh where about 20k users play networked games and exchange electronic items. ${ }^{\text {vii }}$ In 'Citizen Science', open-source hardware platforms like Arduino and Raspberry-Pi are deployed for low-cost and scalable projects generally for environmental monitoring. Finally, the resilience of CWMNs has been occasionally tested by natural or man-made disasters, for example when Hurricane Sandy destroyed most of the communication infrastructure in NYC, Red Hook mesh functioned as an effective back-up in the area. ${ }^{\text {vii }}$

My research on the development of Open Wireless Network (2013-15) revealed that maintaining a mesh of hardware, patching the software, and training people to use it was possible only with a large amount of stewardship from trusted community advocates who themselves had strong technical skills (Cardullo, 2017). We can call them 'ethical hackers', people able to mobilise a good degree of social and technical skills, voluntary work, and some occasional funding. Indeed, the major challenge for community networks is their long-term operation and maintenance, especially when many lay practitioners are involved as the mesh tends to scale horizontally and vertically (as geographical extension and number of users). CWMNs have been experimenting with different models for sustainability and governance, 
the majority relying on voluntary work from activists and contributions from their members to offer Internet connectivity (Cardullo and Roio forthcoming). Usually, node owners buy their hardware: radio, antenna, cables (e.g. Freifunk in Germany, Ninux.org in Italy, S-Net in Havana, OWN in London). Guifi.net in Spain, instead, has been asking members (including commercial operators) to adopt a specific licence, subscribe to an arbitrator agreement and contribute with a fee which includes upgrade and development of the network and also its maintenance. This is carried by senior members, professionals who also offer other telecommunication services over the network (landline telephone or IT support), thus said guided by "clear ideas and strong leadership" (Baig et al. 2015). Finally, Red Hook mesh in NYC offers a model where installation and maintenance are provided by Digital Stewards: these are young residents from the local public housing employed in a paid fellowship (20 hours a week at $\$ 8.75$ an hour), funded by a public grant(Cohen 2017). ${ }^{\text {ix }}$ Whatever the model adopted, every group involved in community networking maintains a local weekly or monthly assembly for face-to-face discussion and problem-solving: for OWN, in London, this was a free training space called 'Wireless Wednesday'. This is because making community operative is an endeavour rooted in social trust, which is a long-term relationship involving at least two things: a place easy to recognise, in the locale where people actually live, and projects that are engaging because deemed 'useful', that is, they are perceived of doing 'something' for their users.

There was another problem affecting the provision of OWN, as with many other public hotspots. One of the hosts of the mesh recalls that, "because of the speed involved, OWN is not good for videos, but it is for general browsing” (in Cardullo 2017). This reminds of the Chattanooga case: speed, bandwidth and cables matter sometimes. Although the mechanism of governance needs to be evaluated case by case, it is tempting to suggest the coming together of public investments in critical infrastructures and the communitarian ethos of sharing and caring (see De Angelis 2017; McLaren and Agyeman 2015; Morozov and Bria 2018; Scholz 2016). These would re-propose the role of the public as a competitive stakeholder beyond the rhetoric of 'market failure' (Mazzucato's argument for 'public value', 2018), while preserving ethos, autonomy and some degrees of informality proper of grass-root organisations. This paper suggests a mixed approach in the provision of the Internet which may be able to satisfy few of the categories above - by way of including grass-root initiatives (in the forms of co-operatives, citizen groups, and social enterprises such as small and ethical 
ISPs), public engagement from the city (as an organisation with social and political goals), and an adequate level of public investments (not only in support of 'market failure').

\section{Concluding remarks}

Are public funds available to cities for the implementation and maintenance of a public Internet service? And, is this a social priority? Indeed, in the prevalent neoliberal framework public investments are admissible only for supporting areas and communities which have fallen through the net of private providers' profit and market imperatives of economic growth. The public strategy for broadband connectivity can be summarised in the catchphrase of 'market failure', that is, public investment should only take place "where the market is not providing the desired connectivity". ${ }^{x}$ Nowadays that the Internet of People and Internet of Things have merged into the 'Smart City', access to a reliable and affordable Internet is not just a matter of geographical inequalities, between the city and the rural or between areas of the same city, and probably neither solely an issue of human rights. It is instead a matter of basic participation to civic life, one gateway for the 'right to the smart city': whether we like or not, digital services are becoming the privileged or only way to pay taxes or parking tickets, to apply for a job or complete school homework, to register a birth or vote: in other words, the way in which people, especially in the Global North, inhabit cities everyday.

For some, it is also a matter of taking the Internet (and, thus, data and the basic privacy rights) back into control and away from the big players and the state. This is a motivation that has traditionally bolstered community networks but it has become, at least in the aims, a policy to be followed by a growing number of cities. From the Fibre-to-Home service to the remote data farms, technology presents itself as a composite assemblage where issues of social justice and democratic governance are to be addressed at each step. Perhaps, not any one city can control the overall process and gain complete "technological and digital sovereignty” (Bria 2017). However, some cities are moving towards the goal of a more favourable access to the Internet, like New York; others have taken further steps by fostering data commons, like Barcelona or Amsterdam. These and other cities have joined together in the 'Cities Coalition for Digital Rights' which aims to show a different path of being 'smart' by supporting practices for preserving citizens' digital rights. ${ }^{x i}$ Morozov and Bria (2018:23) classify these cities into: "those offering an alternative regime for dealing with citizenproduced data; those promoting an alternative, more cooperative model of service provision; 
those seeking to control the activities of platforms like Airbnb or Uber; and those promoting and building alternative infrastructures to compete with Silicon Valley”.

In my view, however, discourses around data and digital commons risk to foster a certain determinism, sometimes focusing more on the object (e.g., a certain data-set or software being made available as common good) rather than the process that leads to and maintains it (commoning). Internet equality claims do not stand as an exception since more connected people do not translate automatically into fairer communities, nor more liveable cities. This is because cities are messy and complex places and because infrastructures are sociotechnological assemblages that depend for their functioning on the practices, uses, and therefore skills of those involved around the milieu they foster. With algorithm-led technologies, this assumption is often subsumed to the process of acquiring data, selecting optimal profiles and responses, and enabling feedback. Thus, there is room for a conclusive cautionary note around the the implementation and maintenance of a public network, with two issues in relation to community involvement and commoning in the 'smart city'.

The first one concerns the substantial differences between algorithm trust and social trust: people and things are actuators of the data exchange through networks, continuously performing acts of 'trust' at the margin of the mesh. But while algorithm trust happens in milliseconds between long alphanumeric keys which recognise each others and perform a socalled 'handshake', social trust hinges on long term relationships and slow exchanges often performed face to face in the spaces of daily inhabitation and around social spaces shared in commons. Here, there is room for ethical hackers and community organisers with strong technical skills to mobilize knowledge transfer and try to limit digital divides, and for people to get actively involved in the making or maintenance of technologies in social space. But smart city innovations risk to foster exclusionary outcomes, because city space itself - the spaces of social reproduction and production of the commons - is increasingly divided by 'rent', which displaces both communitarian hacktivists and local residents (Cardullo 2017).

Moreover, and second issue, we can draw a vector of possibilities along the determinants of stewardship and socio-technical skills, both needed to maintain smart technologies as a working infrastructure. Provision of the Internet for people and 'things' require medium level stewardship and skills; however, stewardship becomes essential with regard to communitarian networks because the higher the involvement of lay people the harder it will become to include them in the development and deployment of the technology. Smart technologies 
demand often the deployment of cultural and social capitals, because they are linked to social exchange and their implementation is conditional to contextual arrangements in communities of interest and localities: that is, there is nothing automatic and deterministic about platforms and sensors in making communities 'operative'. Moreover, some of the technologies currently deployed in the smart city are beyond people's agentive interaction with their computational processes enabling black-boxed, autonomous and automated responses.

Rather than an heroic immersion in the back alleys of cybernetics (which would focus on protocol exchange, encryption, blockchain, and other technical solutions), the paper suggests a pragmatic approach to commons in the smart city. This approach would consider, for instance, that the myriad of citizen-science and crowdsourced projects and communitarian networks suffer from conspicuous stewardship and long term maintenance, resources, and scalability issues, which maybe cities can support by taking the backbone under their own capacity and favouring municipalised or cooperative enterprises, such as small and ethical ISPs. Conversely, there is an uncertain role of the city in drawing policies that support (or hinder) the inclusion of communities, devolve (or take) power to (from) citizens, and enact (or re-centralise) forms of open and democratic governance. This is because there is more public and political awareness around the data extractive practices of digital capitalism, the surveillance capabilities of commercial and state players, and the monopolistic regime in which Internet Service Providers (ISPs) operate.

The paper plots this trajectory showing that cities have a lot to learn and gain from the commons: citizens might even be able to shift their role of 'consumers' and regain some accountability, privacy and, eventually, control over technologies (e.g., Cardullo and Kitchin 2018a). As McLaren and Agyeman suggest (2015:1), "good governance and collective city structures” are what successful cities need. Here, of course, the key words are 'good' and 'collective', which require a more articulate response than this paper can offer. These are ethical and political questions: in what forms these modalities are combined is difficult to forecast and should be evaluated case by case. The paper contends though that an alliance between city and the commons, rather than the market, can start removing some of the barriers in the adoption of technologies which depend heavily on the Internet of People and Things. 


\section{Acknowledgements}

The research for this paper was provided by a European Research Council Advanced Investigator Award, 'The Programmable City' (ERC-2012-AdG-323636). Many thanks to Rob Kitchin and Cesare di Feliciantonio for their editing suggestions and comments, and to the attendees of the 'After the smart city? The state of critical scholarship ten years on' sessions at the Association of American Geographers meeting in New Orleans, April 2018, for their useful comments. A shorter version of this paper will appear in Kitchin, R., Cardullo, P., and Di Feliciantonio, C., eds., 2019. The Right to the Smart City. Emerald Publishing. 
i_ https://ec.europa.eu/digital-single-market/en/news/broadband-big-pipes-potential-growth

ii For instance, https://ec.europa.eu/digital-single-market/en/blog/objective-2017-more-investments-digital;

see also: https://www.cbpp.org/research/poverty-and-inequality/fcc-broadband-initiative-could-reducebarriers-to-low-income

iii https://qz.com/333313/milliions-of-facebook-users-have-no-idea-theyre-using-the-internet/

iv A handful of towns are following now on the example offered by Chattanooga, for instance Hopkinsville, Kentucky, https://hop-electric.com/news/introducing-the-new-energynet/

v_ https://www.nytimes.com/2018/06/11/technology/net-neutrality-repeal.html

vi Recently closed after H\&S and Fire regulation checks by Greenwich Council, http://wrd.spc.org/described/deckspace/

vii Snet is not offering a gateway to the public Internet since connectivity in Cuba is patchy and limited to public parks and schools because of the US embargo and restrictive local policies.

viiiHowever, since CWMNs operate in unlicensed frequency bands which are subject to uncontrolled interference from a range of sources and overcrowding, their efficacy during emergency is disputed.

ix_https://www.nytimes.com/2014/08/24/nyregion/red-hooks-cutting-edge-wireless-network.html

$\mathrm{x}$ _https://ec.europa.eu/digital-single-market/en/state-aid

xi_https://citiesfordigitalrights.org/actions.html

\section{References}

Baig, Roger, Ramon Roca, Leandro Navarro, and Felix Freitag. 2015. 'Guifi.Net: A Network Infrastructure Commons'. Pp. 1-4 in Proceedings of the Seventh International Conference on Information and Communication Technologies and Development - ICTD '15. Singapore, Singapore: ACM Press.

Birkinbine, Benjamin J. 2018. 'Commons Praxis: Toward a Critical Political Economy of the Digital Commons'. TripleC: Communication, Capitalism \& Critique. Open Access Journal for a Global Sustainable Information Society 16(1):290-305.

Bria, Francesca. 2017. 'Building the Networked City from the Ground up with Citizens'. OuiShare EN - Connecting the Collaborative Economy. Retrieved 4 August 2017 (http://bit.ly/2tLPpMp).

Cardullo, Paolo. 2015. 'Hacking Multitude and Big Data: Some Insights from the Turkish Digital Coup'. Big Data \& Society.

Cardullo, Paolo. 2017. 'Gentrification in the Mesh?' City 21(3-4):405-19.

Cardullo, Paolo and Rob Kitchin. 2018a. 'Being a "Citizen” in the Smart City: Up and down the Scaffold of Smart Citizen Participation in Dublin, Ireland'. GeoJournal 1-13.

Cardullo, Paolo and Rob Kitchin. 2018b. 'Smart Urbanism and Smart Citizenship: The Neoliberal Logic of “Citizen-Focused” Smart Cities in Europe'. Environment and Planning C: Politics and Space.

Cardullo, Paolo, Rob Kitchin, and Cesare Di Feliciantonio, eds. 2019. The Right to the Smart City. Emerald Publishing. 
Cardullo, Paolo and Denis Roio. forthcoming. 'Mesh Networking'. Wiley Blackwell Encyclopedia of Sociology 2nd Edition.

Cohen, Noam. 2017. 'Red Hook’s Cutting-Edge Wireless Network'. The New York Times, December 20.

Couldry, Nick. 2018. 'The Price of Connection'. HIIG. Retrieved 22 November 2018 (https://www.hiig.de/en/the-price-of-connection/).

Curran, Nathaniel Ming. 2018. 'A Reflection on South Korea’s Broadband Success'. Media, Culture \& Society.

Davidson, Charles and Michael Santorelli. 2015. Understanding the Debate over Government-Owned Broadband Networks.

De Angelis, Massimo. 2001. 'Marx and Primitive Accumulation: The Continuous Character of Capital's “Enclosures””. The Commoner 2.

De Angelis, Massimo. 2017. Omnia Sunt Communia: On the Commons and the Transformation to Postcapitalism. Zed Books.

De Angelis, Massimo and Stavros Stavrides. 2010. 'On the Commons: A Public Interview with Massimo De Angelis and Stavros Stavrides’. An Architektur, e-Flux, June.

EPB. 2015. 'EPB to Offer Discounted Internet for Low-Income Families'. EPB | Powering Chattanooga. Retrieved 27 March 2018 (https://epb.com/about-epb/news/articles/8).

Foth, Marcus. 2017. 'The Software-Sorted City: Big Data \& Algorithms'. in Digital Cities 10: Towards a Localised Socio-Technical Understanding of the 'Real' Smart City, edited by N. Odendaal and A. Aurigi. Troyes, France.

Gonzalez, Lisa. 2018. 'Grassroots Group Forming to Take Action on Broadband in Massachusetts City’. Institute for Local Self-Reliance. Retrieved 29 March 2018

(https://ilsr.org/grassroots-group-forming-to-take-action-on-broadband-in-massachusettscity/).

Hardt, Michael and Antonio Negri. 2009. Commonwealth. Cambridge, Mass: Belknap Press of Harvard University Press.

Harvey, David. 2003. 'The Right to the City'. International Journal of Urban and Regional Research 27(4):939-940.

Hollands, Robert G. 2008. 'Will the Real Smart City Please Stand up? Intelligent, Progressive or Entrepreneurial?' City 12(3):303-320.

Hu, Tung-Hui. 2015. A Prehistory of the Cloud. Cambridge, Massachusetts: The MIT Press. Huron, Amanda. 2015. 'Working with Strangers in Saturated Space: Reclaiming and Maintaining the Urban Commons: The Urban Commons'. Antipode 47(4):963-79.

Iaione, Christian. 2012. 'City as a Commons'. in Second Thematic Conference of the IASC on "Design and Dynamics of Institutions for Collective Action: A Tribute to Prof. Elinor Ostrom. Vol. 29.

Illich, Ivan. 1982. 'Silence Is a Commons'. The CoEvolution Quarterly.

Kitchin, Rob. 2014. 'Big Data, New Epistemologies and Paradigm Shifts'. Big Data \& Society 1(1):205395171452848.

Kitchin, Rob. 2016. 'The Ethics of Smart Cities and Urban Science'. Phil. Trans. R. Soc. A 374(2083):20160115.

Kitchin, Rob, Claudio Coletta, Leighton Evans, Liam Heaphy, and Darach MacDonncha. 2017. 'Smart Cities, Epistemic Communities, Advocacy Coalitions and the `last Mile' Problem'. It - Information Technology 0(0).

Kitheka, Bernard M., Elizabeth D. Baldwin, David L. White, and Daniel N. Harding. 2016. 'A Different "We" in Urban Sustainability: How the City of Chattanooga, TN, Community Defined Their Own Sustainability Path'. International Journal of Tourism Cities 2(3):185- 
205.

Koebler, Jason. 2016. 'The City That Was Saved by the Internet'. Motherboard, October 27. de Lange, Michiel and Martijn de Waal. 2013. 'Owning the City: New Media and Citizen Engagement in Urban Design'. First Monday 18(11).

Lash, Scott. 2002. Critique of Information. London ; Thousand Oaks, Calif: SAGE. Lazonick, William and Mariana Mazzucato. 2013. 'The Risk-Reward Nexus in the Innovation-Inequality Relationship: Who Takes the Risks? Who Gets the Rewards?' Industrial and Corporate Change 22(4):1093-1128.

Lefebvre, Henri. 1996. 'The Right to the City'. in Writings on cities, edited by E. Kofman and E. Lebas. Cambridge, Mass: Blackwell.

Lewis-Kraus, Gideon. 2016. 'The Battle to Bring Broadband to New York’s Public Housing'. Wired, November 3.

Luque-Ayala, Andrés and Simon Marvin. 2016. 'The Maintenance of Urban Circulation: An Operational Logic of Infrastructural Control'. Environment and Planning D: Society and Space 34(2):191-208.

Mabud, Rakeen and Marybeth Seitz-Brown. 2017. Wired: Connecting Equity to a Universal Broadband Strategy. the Roosevelt Institute.

Marcuse, Peter. 2009. 'From Critical Urban Theory to the Right to the City'. City 13(2):185-97.

Mazzucato, Mariana. 2018. The Value of Everything: Makers and Takers in the Global Economy. London: Allen Lane.

McLaren, Duncan and Julian Agyeman. 2015. Sharing Cities: A Case for Truly Smart and Sustainable Cities. Cambridge: MIT Press.

Medosch, Armin. 2003. Freie Netze. Hannover: Heise Heinz.

Mezzadra, Sandro and Brett Neilson. 2017. 'On the Multiple Frontiers of Extraction:

Excavating Contemporary Capitalism’. Cultural Studies 31(2-3):185-204.

Monnier, Jean-Marie and Carlo Vercellone. 2017. Basic Income as Primary Income. Université Paris1 Panthéon-Sorbonne (Post-Print and Working Papers). HAL.

Morozov, Evgeny. 2015. 'Socialize the Data Centres!' New Left Review (91):45-66.

Morozov, Evgeny and Francesca Bria. 2018. 'Rethinking the Smart City'. Rosa Luxemburg Stiftung Nyc.

Picon, Antoine. 2015. Smart Cities: A Spatialised Intelligence. Chichester, West Sussex:

Wiley.

Plantin, Jean-Christophe and Aswin Punathambekar. 2018. 'Digital Media Infrastructures:

Pipes, Platforms, and Politics’. Media, Culture \& Society 0163443718818376.

Rushe, Dominic. 2014. 'Chattanooga’s Gig: How One City’s Super-Fast Internet Is Driving a Tech Boom'. The Guardian, August 30.

Sadowski, Jathan and Frank A. Pasquale. 2015. 'The Spectrum of Control: A Social Theory of the Smart City'.

Scholz, Trebor. 2016. 'Platform Cooperativism'. Rosa Luxemburg Stiftung Nyc.

Shaw, Joe and Mark Graham. 2017. 'An Informational Right to the City? Code, Content, Control, and the Urbanization of Information': Antipode 49(4):907-27.

Shelton, Taylor, Matthew Zook, and Alan Wiig. 2015. 'The “Actually Existing Smart City”. Cambridge Journal of Regions, Economy and Society 8(1):13-25.

Skeggs, Beverly and Simon Yuill. 2018. 'Subjects of Value and Digital Personas: Reshaping the Bourgeois Subject, Unhinging Property from Personhood'. Subjectivity.

Stavrides, Stavros. 2016. Common Space: The City as Commons. Zed Books Ltd. 
Susser, Ida. 2017. 'For or against Commoning?’ Focaal 2017(79):1-5.

Thatcher, Jim, David O’Sullivan, and Dillon Mahmoudi. 2016. 'Data Colonialism through Accumulation by Dispossession: New Metaphors for Daily Data'. Environment and Planning D: Society and Space 34(6):990-1006.

Townsend, Anthony. 2013. 'Introduction: Urbanization and Ubiquity'. in Smart Cities: Big Data, Civic Hackers, and the Quest for a New Utopia. W. W. Norton \& Company.

Vanolo, Alberto. 2014. 'Smartmentality: The Smart City as Disciplinary Strategy'. Urban Studies 51(5):883-99. 